\title{
Pulmonary complications in primary hypogammaglobulinemia: a survey by high resolution $C T$ scan
}

\author{
M. Gharagozlou, F.A. Ebrahimi, A. Farhoudi, A. Aghamohammadi, \\ M.-H. Bemanian, Z. Chavoshzadeh, M. Heidarzadeh, M. Mehdizadeh, \\ M. Moin, M. Movahedi, M. Nabavi, Z. Pourpak, N. Rezaei
}

ABSTRACT: Pulmonary complications in primary hypogammaglobulinemia: a survey by high resolution $C T$ scan. M. Gharagozlou, F.A. Ebrahimi, A. Farhoudi, A. Aghamohammadi, M.-H. Bemanian, Z. Chavoshzadeh, M. Heidarzadeh, M. Mehdizadeh, M. Moin, M. Movahedi, M. Nabavi, Z. Pourpak, N. Rezaei.

Background. Primary hypogammaglobulinemia disorders are a group of heterogeneous immunodeficiency syndromes with an increased susceptibility to pulmonary complications.

Methods. The aim of this study was to evaluate the extent of lung abnormalities in primary hypogammaglobulinaemic patients by high resolution computed tomography (HRCT) scan and pulmonary function test (PFT). HRCT and PFT were performed in 22 Iranian patients with primary hypogammaglobulinemia.

Results. Pathological bronchial findings were observed in thirteen patients: three patients showed only peribronchial thickening and the remaining ten patients suffered from both bronchiectasis and peribronchial wall thickening. Mild type of bronchiectasis and peribronchial wall thickening were the most common type, predomi- nantly observed in the right middle and both right and left lower lobe segments of lungs. Although bullae were not found, emphysema, air-trapping, and collapse/consolidation were observed in two patients. Bronchial involvement was mostly limited to 1 up to 5 bronchopulmonary segments; only one HRCT indicated bronchial involvement in more than nine bronchopulmonary segments. Pathological bronchial findings mostly observed in the proximal bronchi; meanwhile the involvement of the distal bronchi was less common. Decreasing $\mathrm{FEV}_{1}$ and FVC were observed in $65 \%$ and $55 \%$ of patients, respectively. There was a significant correlation between the HRCT score and the predicted values by PFT. The delay of diagnosis in patients with bronchiectasis was significantly higher than those without bronchiectasis.

Conclusions. It seems that the majority of hypogammaglobulinaemic patients suffer from the mild type of bronchiectasis, which is mostly observed in the proximal bronchi of the lower lobe segments. The delay of diagnosis plays an important role in the occurrence of this complication in these patients.

Monaldi Arch Chest Dis 2006; 65: 2, 69-74.

Keywords: Computed tomography, hypogammaglobulinemia, Iran, pulmonary complications.

Department of Allergy and Clinical Immunology, Immunology, Asthma and Allergy Research Institute, Tehran University of Medical Sciences, Tehran, Iran.

Correspondence: Mohammad Gharagozlou, MD, Department of Allergy and Clinical Immunology, Children Medical Center, No.62, Dr. Gharib St., Keshavarz.Blvd., Tehran 14194,Iran; e-mail: rezaei_nima@hbi.ir, gharagoz@tums.ac.ir

\section{Introduction}

Primary hypogammaglobulinemia consists of a heterogeneous group of disorders including: $\mathrm{X}$ linked agammaglobulinemia (XLA), common variable immunodeficiency (CVID), IgA deficiency, selective subclass IgG deficiency, functional antibody defect, and transient hypogammaglobulinemia. In all of these disorders, the impaired antibody response to pathogens leads to an increased susceptibility to bacterial infections, especially in the respiratory system [1-3]. Recurrent respiratory infections cause serious complications that lead to morbidity and mortality in these patients $[1,2]$. Early diagnosis and appropriate treatments are very important in preventing the deterioration of pulmonary function [4]. The exact identification of pulmonary complications could be made using a high resolution computed tomography (HRCT) scan. The high sensitivity and specificity of HRCT in showing irreversible and significant bronchiectasis, which is the most important complication in these patients, and also its advantages over the other procedures, made it the most preferably procedure [5-10]. This study was performed to evaluate the extent of lung abnormalities in primary hypogammaglobulinaemic patients using the HRCT scoring system and also assessing the pulmonary function test (PFT). We also analysed the correlation between the score from HRCT and pulmonary function data $\left(\mathrm{FEV}_{1}\right.$ and $\left.\mathrm{FVC}\right)$.

\section{Patients and methods}

Twenty two patients (14 males and 8 females) with the median age of 15 years (range: 2-28 
years) were investigated in this study. These hypogammaglobulinaemic patients (13 CVID and 9 XLA) were referred to the Department of Allergy and Clinical Immunology of Children Medical Center, Tehran, Iran during 2001-2005. All clinical information was extracted from the patients' records and also by interviewing the patients and their parents. The HRCT scans and pulmonary function test (PFT) were carried out in these patients. PFT was not performed in 2 patients because of their low age.

Only male patients with the low level of Bcells (CD19+ less than 1\%) - shown by immunoflowcytometry - and having the following criteria, were included as XLA in this study:

1. The low levels of serum IgG, IgM and $\operatorname{IgA}$ (more than 2 Standard Deviation below the normal levels for the age), which were determined by radioimmunodiffusion and proved by nephelometry;

2. Lack of proper antibody response which was proved by measuring the isohemaglutinin titer or Schick test; and

3. Exclusion of other diseases leading to hypogammaglobulinemia.

Diagnosis of CVID is based on the decreased serum level of at least two immunoglobulins (more than 2 Standard Deviation below the normal level for that age) and exclusion of other causes of hypogammaglobulinemia like Hyper-IgM syndromes, Selective IgA deficiency, Subclass IgG deficiency, and transient hypogammaglobulinemia.
HRCT and PFT were performed individually for the patients. The standard high resolution technique in this study consists of scanning at full inspiration using $1.5 \mathrm{~mm}$ thick section with $10 \mathrm{~mm}$ spacing, and displaying the images with high resolution (bone) algorithm at lung windows (width $1500-2000$, length -500 to -700 ). All HRCT scans and PFT tests were performed after standard physiotherapy and in the absence of undercurrent acute illness. The HRCT scoring system was used for evaluating the extent of lung abnormalities in HRCT [11] (table 1). In this system, the score is shown by the numbers 0-3 for the following information: a) Severity of bronchiectasis; b) Peribronchial thickening; c) Extent of bronchiectasis; d) Extent of mucus plug; e) Sacculation; f) Generations of bronchi involved; g) Number of bullae; h) Emphysema; and I) collapse/consolidation. Bronchiectasis as the main pulmonary complications of hypogammaglobulinemia, characterised by permanent dilation of bronchi; HRCT is the gold standard for detection of bronchiectasis. In order to determine the total score for each patient, the scores of each scan was subtracted from a potentially perfect total score of 25. A total score of below 22 was considered to be an abnormal score. All scans were scored by two expert radiologists, who were blinded to all clinical information. The inter-observer reliability of the scoring system was tested and expressed as a standard deviation of scores obtained by two observers within individual patients. The standard deviation was averaged across all patients and was obtained from the vari-

Table 1. - The high resolution computed tomography (HRCT) Scoring System

\begin{tabular}{|c|c|c|c|c|}
\hline \multirow[b]{2}{*}{ Category } & \multicolumn{4}{|c|}{ HRCT Score } \\
\hline & $\mathbf{0}$ & $\begin{array}{c}1 \\
\text { mild }\end{array}$ & $\stackrel{2}{\text { moderate }}$ & $\begin{array}{c}3 \\
\text { severe }\end{array}$ \\
\hline Severity of bronchiectasis & Absent & $\begin{array}{l}\text { Luminal diameter slightly } \\
\text { greater than diameter } \\
\text { of adjacent blood vessel }\end{array}$ & $\begin{array}{l}\text { Lumen 2-3 times } \\
\text { the diameter of vessel }\end{array}$ & $\begin{array}{l}\text { Lumen }>3 \text { times } \\
\text { diameter of vessel }\end{array}$ \\
\hline Peribrochial thickening & Absent & $\begin{array}{l}\text { Wall thickness equal } \\
\text { to diameter } \\
\text { of adjacent vessel }\end{array}$ & $\begin{array}{l}\text { Wall thickness greater } \\
\text { than and up to twice } \\
\text { the diameter } \\
\text { of adjacent vessel }\end{array}$ & $\begin{array}{c}\text { Wall thickness } \\
>2 \text { times } \\
\text { the diameter } \\
\text { of adjacent vessel }\end{array}$ \\
\hline Extent of bronchiectasis & Absent & $1-5(\mathrm{BP})$ & $6-9(\mathrm{BP})$ & $>9(\mathrm{BP})$ \\
\hline Extent of mucus plugging & Absent & $1-5(\mathrm{BP})$ & 6-9(BP) & $>9(\mathrm{BP})$ \\
\hline Sacculation & Absent & $1-5(\mathrm{BP})$ & $6-9(\mathrm{BP})$ & $>9(\mathrm{BP})$ \\
\hline $\begin{array}{l}\text { Generation of bronchial } \\
\text { divisions involved } \\
\text { (bronchiectasis/plugging) }\end{array}$ & Absent & Up to $4^{\text {th }}$ generation & Up to $5^{\text {th }}$ generation & $\begin{array}{l}\text { Up to } 6^{\text {th }} \text { generation } \\
\text { and distal }\end{array}$ \\
\hline No. of bullae & Absent & Unilateral (not>4BP) & Bilateral (not>4BP) & $>4 \mathrm{BP}$ \\
\hline Emphysema & Absent & $1-5(\mathrm{BP})$ & $>5(\mathrm{BP})$ & \\
\hline Collapse/Consolidation & Absent & Subsegmental & Segmental/lobar & \\
\hline
\end{tabular}

BP: Bronchopulmonary segments. 
ance estimate in a mixed-model two-way analysis of variance.

PFT was performed in twenty patients, who did not have acute respiratory illness at that time. Force vital capacity (FVC) and force expiratory volume in one second $\left(\mathrm{FEV}_{1}\right)$ were obtained with a Jaeger Master lab Spirometer (Erich Jaeger, Wurzburg, Germany). All values were depicted as percentage of the predicted values. Decreased $\mathrm{FEV}_{1}$ or FVC values have been classified as mild $\left(\% 60<\mathrm{FEV}_{1}\right.$ or FVC $<\% 80)$, moderate $\left(\% 40<\mathrm{FEV}_{1}\right.$ or $\left.\mathrm{FVC}<\% 60\right)$, or severe $\left(\mathrm{FEV}_{1}\right.$ or $\left.\mathrm{FVC}<40 \%\right)$.

We examined the validity of the HRCT scoring system by analysing the correlation between the pulmonary function data $\left(\mathrm{FEV}_{1}\right.$ and $\left.\mathrm{FVC}\right)$ and the score of each patient. The correlation between the pulmonary function data and the HRCT scores was measured with a linear regression model. All statistical analyses were performed by the SPSS statistical software package version 10.0. The independent - sample $t$ test was used for quantitative variables. The level for statistical significance was $\mathrm{p}<0.05$.

\section{Results}

Twenty-two patients with primary hypogammaglobulinemia were evaluated for the extent of pulmonary complications by HRCT scans. A randomised complete block analysis of the data was performed on the basis of an independent observation by two radiologists who reviewed twenty-two scans for the nine parameters. The inter-observer variability for the scores had a standard deviation of 1.05 .

The HRCT scans revealed abnormality in 13 out of 22 patients (table 2). The scan of ten out of thirteen patients showed both bronchiectasis and peribronchial thickening. There were three patients with peribronchial wall thickening without bronchiectasis. Most of the patients had a mild

Table 2. - The results of high resolution computed tomography (HRCT) in 22 patients with primary hypogammaglobulinemia

\section{HRCT Score}

Mild Moderate Severe

\begin{tabular}{llll}
\hline Severity of bronchiectasis & 7 & 2 & 1 \\
Peribronchial thickening & 9 & 4 & 0 \\
Extent of bronchiectasis & 7 & 2 & 1 \\
Extent of mucus plugging & 7 & 0 & 2 \\
Sacculation & 0 & 0 & 0 \\
$\begin{array}{l}\text { Generation bronchial } \\
\text { division involved }\end{array}$ & 7 & 4 & 1 \\
No. of bullae & 0 & 0 & 0 \\
Emphysema & 1 & 1 & 0 \\
Collapse/Consolidation & 1 & 1 & 0 \\
\hline
\end{tabular}

type of peribronchial thickening and bronchiectasis $(69 \%$ and $70 \%$, respectively). The bronchial involvement and mucus plug were mostly limited to 1 up to 5 bronchopulmonary segments $(70 \%$ and $77 \%$, respectively); only one scan showed bronchial involvement in more than nine bronchopulmonary segments. Although bulla was not found, emphysema, air-trapping, and collapse/consolidation were observed in two patients. Considering the main-stem bronchi as the first-generation of bronchial divisions, bronchial involvement mostly extended up to the forth generation of bronchial divisions $(53 \%)$. The HRCT score ranged between 12 and 25; the score of nine patients was below twenty-two, which is considered to be an abnormal score.

Peribronchial wall thickening and bronchiectasis were predominant in the right middle and lower lobe segments and also in the lower division of left upper lobe and left lower lobe segments (table 3). The involvement of right upper lobe and the upper division of the left upper lobe segments were rare.

The delay of diagnosis in patients with bronchiectasis was significantly higher than those without bronchiectasis $(100.27 \pm 10.2$ vs. $43.93 \pm 1.8$ months, $\mathrm{p}=0.016$ ) (table 4).

13 out of 20 patients $(65 \%)$ showed decreased $\mathrm{FEV}_{1}$ values ( $<80 \%$ of predicted value) in PFT tests (table 5). Mild, moderate and severe decreas-

Table 3. - Patterns of lung involvement in 22 patients with primary hypogammaglobulinemia studied by HRCT scan

\begin{tabular}{|c|c|c|}
\hline & Bronchiectasis & $\begin{array}{c}\text { Peribronchial } \\
\text { thickening }\end{array}$ \\
\hline \multicolumn{3}{|l|}{ Right upper lobe } \\
\hline Apical & 0 & 2 \\
\hline Anterior & 3 & 5 \\
\hline Posterior & 3 & 3 \\
\hline \multicolumn{3}{|l|}{ Right middle lobe } \\
\hline Lateral & 6 & 6 \\
\hline Medial & 4 & 5 \\
\hline \multicolumn{3}{|l|}{ Right lower lobe } \\
\hline Superior & 3 & 3 \\
\hline Medial basal & 5 & 5 \\
\hline Anterior basal & 4 & 4 \\
\hline Posterior basal & 5 & 5 \\
\hline Lateral basal & 5 & 4 \\
\hline \multicolumn{3}{|l|}{ Left upper lobe } \\
\hline \multicolumn{3}{|l|}{ Upper division } \\
\hline Apicoposterior & 2 & 3 \\
\hline Anterior & 2 & 3 \\
\hline \multicolumn{3}{|l|}{ Lower division } \\
\hline Superior & 7 & 6 \\
\hline Inferior & 5 & 6 \\
\hline \multicolumn{3}{|l|}{ Left lower lobe } \\
\hline Superior & 5 & 8 \\
\hline Anterormedial & 6 & 9 \\
\hline Lateral & 5 & 7 \\
\hline Posteriorbasal & 6 & 8 \\
\hline
\end{tabular}


Table 4. - Characteristics of primary hypogammaglobulinemia patients regarding the presence of bronchiectasis by $\operatorname{HRCT}(\mathrm{n}=22)$

\begin{tabular}{lccc}
\hline & Patients with bronchiectasis & Patients without bronchiectasis & P-value \\
\hline Mean age (months) & $212.9 \pm 14.2$ & $163.45 \pm 11.9$ & 0.12 \\
Mean onset age of symptoms (months) & $27.84 \pm 1.2$ & $31.12 \pm 1.8$ & 0.34 \\
Duration of disease (months) & $184.25 \pm 13.2$ & $132.33 \pm 13.4$ & 0.21 \\
Duration of treatment (months) & $71.14 \pm 3.2$ & $81.38 \pm 3.6$ & 0.11 \\
Delay of diagnosis (months) & $100.27 \pm 10.2$ & $43.93 \pm 1.8$ & 0.016 \\
\hline
\end{tabular}

Table 5. - PFT findings of 20 patients with primary hypogammaglobulinemia

\begin{tabular}{|c|c|c|c|c|c|c|}
\hline Number & Sex & Diagnosis & $\begin{array}{c}\mathrm{FEV}_{1} \\
(\% \text { of predicted) }\end{array}$ & $\begin{array}{c}\text { FVC } \\
\text { (\% of predicted) }\end{array}$ & $\mathrm{FEV}_{1} / \mathrm{FVC}(\%)$ & $\begin{array}{l}\text { HRCT } \\
\text { Score }\end{array}$ \\
\hline 1 & Female & CVID & 87.9 & 79.3 & 100.0 & 25 \\
\hline 2 & Male & XLA & 107.9 & 106.5 & 91.8 & 20 \\
\hline 3 & Male & CVID & 28.3 & 26.5 & 97.2 & 13 \\
\hline 4 & Male & XLA & 76.7 & 77.1 & 90.0 & 19 \\
\hline 5 & Female & CVID & 86.9 & 83.9 & 94.5 & 25 \\
\hline 6 & Male & XLA & 75.4 & 73.6 & 92.7 & 25 \\
\hline 7 & Male & CVID & 68.1 & 76.1 & 80.9 & 16 \\
\hline 8 & Male & CVID & 78.3 & 79.9 & 89.0 & 25 \\
\hline 9 & Female & CVID & 61.4 & 58.9 & 94.5 & 25 \\
\hline 10 & Male & XLA & 88.8 & 80.6 & 100.0 & 24 \\
\hline 11 & Male & XLA & 18.3 & 22.0 & 75.4 & 14 \\
\hline 12 & Male & XLA & 82.2 & 79.7 & 93.6 & 22 \\
\hline 13 & Female & CVID & 47.0 & 45.0 & 94.5 & 19 \\
\hline 14 & Female & CVID & 111.5 & 97.6 & 103.6 & 25 \\
\hline 15 & Female & CVID & 65.9 & 61.2 & 98.1 & 22 \\
\hline 16 & Male & CVID & 64.7 & 74.1 & 79.0 & 17 \\
\hline 17 & Male & CVID & 49.4 & 44.6 & 100.9 & 16 \\
\hline 18 & Male & XLA & 123.9 & 106.9 & 105.4 & 25 \\
\hline 19 & Male & CVID & 98.3 & 94.5 & 94.5 & 25 \\
\hline 20 & Female & CVID & 37.6 & 34.2 & 99.0 & 12 \\
\hline
\end{tabular}

XLA: X-linked agammaglobulinemia; CVID: Common variable immunodeficiency.

es of $\mathrm{FEV}_{1}$ values were observed in $35 \%, 20 \%$ and $10 \%$ of patients, respectively. Eleven patients $(55 \%)$ showed decreased FVC values $(<80 \%$ of predicted value). Mild, moderate and severe decreases of FVC values were observed in $35 \%, 10 \%$ and $10 \%$ of patients, respectively. Statistical analysis demonstrated a significant correlation between the HRCT score and the percentage predicted values of either $\mathrm{FEV}_{1}(\mathrm{r}=0.69, \mathrm{p}=0.006)$ or $\mathrm{FVC}$ $(r=0.72, p=0.002)$ (figure 1); however, there was not any significant correlation between HRCT score and $\mathrm{FEV}_{1} / \mathrm{FVC}(\mathrm{r}=0.39, \mathrm{p}=0.089)$.

\section{Discussion}

Recurrent lung suppurative infections predispose the primary hypogammaglobulinaemic patients to serious pulmonary complications, which often lead to significant morbidity and mortality in these patients [1]. In our study, we observed parenchymal involvement besides pathological bronchial findings. This was in contrast to some other studies, which showed only the bronchial involvement $[12,13]$. The parenchymal involvements including collapse and consolidation were seen in approximately $20 \%$ of our patients; the delay of diagnosis that leads to an increased risk of pulmonary infections may be the possible reason for these findings in our patients' group. Bronchiectasis, the most important pathological bronchial findings, was observed in $45 \%$ of our patients, which is very different from previous studies $[14,15,16]$. This may be presumably due to differences in the delay of diagnosis, which plays an important role in the occurrence of this complication according to our results. In addition patients 


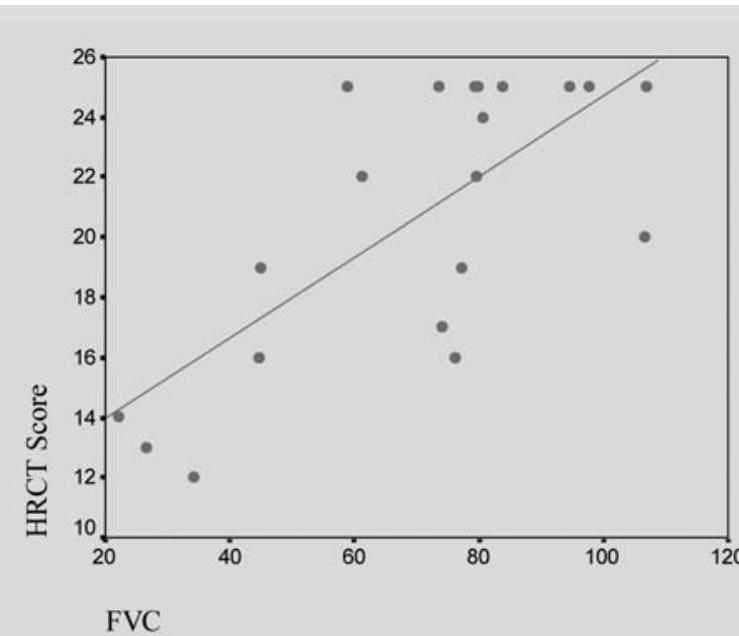

$\mathbf{r}=\mathbf{0 . 7 2}, \mathrm{p}=\mathbf{0 . 0 0 2}$

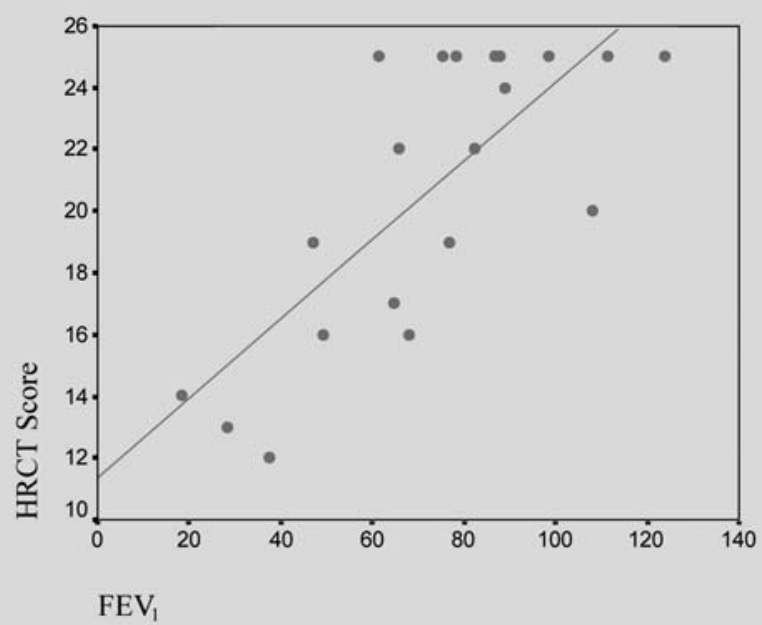

$\mathrm{r}=\mathbf{0 . 6 9}, \mathrm{p}=\mathbf{0 . 0 0 6}$

Fig. 1. - The correlation of HRCT score and the percentage predicted values of FVC (top) and $\mathrm{FEV}_{1}$ (bottom) in 20 patients.

with XLA have lower serum levels of immunoglobulins and higher susceptibility to respiratory infections in the lower ages, which rapidly move towards deterioration of bronchial tracts $[1,2]$. We also observed that despite of immunodeficiency, bronchial involvements were mostly limited to 1 up to 5 segments. Most of the patients suffered from mild bronchiectasis, which is mainly confined to proximal bronchi.

Peribronchial wall thickening was also observed in $59 \%$ of our patients, which was much higher than in the studies by Curtin [14] and Feydy's [13] and much lower than in the study by Obregon [12]. These differences may be due to differences in protocols, image displays, and the subjectivity in diagnosing bronchial wall thickening.

We observed that peribronchial wall thickening and bronchiectasis were predominantly seen in the right middle and both right and left lower lobe segments. The occurrence of bronchiectasis and peribronchial wall thickening in the same segments and non-appearance of bronchiectasis by it- self emphasises this theory that peribronchial wall thickening could be an early sign of the bronchial inflammation, which could progress and eventually lead to permanent bronchiectasis [13].

In the previous review of patients with cystic fibrosis, Bhalla et al [11] introduced a HRCT scoring system, which demonstrated a statistically significant correlation with $\mathrm{FEV}_{1} / \mathrm{FVC}$, thereby reflecting the extent of airways disease and secondary obstructive changes. The scoring system, which is fairly simple to perform, attempts to standardise the extent and severity of chronic lung disease. We tried to apply this scoring system to a population of patients, who were also at risk of bronchiectasis and chronic lung diseases. We showed that there were statistically significant correlations between HRCT scores and the percentage predicted values of either $\mathrm{FEV}_{1}$ or $\mathrm{FVC}$; however, there was not any significant correlation between HRCT score and $\mathrm{FEV}_{1} / \mathrm{FVC}$. The scoring system proved to have excellent interobserver reliability. The interobserver variability for the scores had a standard deviation of 1.05. As it was predicted, there were some disagreement points in the scoring of severity of bronchiectasis and peribronchial thickening because the assessment is based on the subjectivity of these parameters.

This study showed that the majority of hypogammaglobulinaemic patients suffer from the mild type of bronchiectasis, which is mostly observed in the proximal bronchi of the lower lobe segments. Moreover the delay in diagnosis predisposes these patients to this complication. The HRCT scoring system seems to be a reliable and valuable technique in demonstrating the extent and severity of chronic lung disease in this group of patients.

\section{References}

1. Rosen FS, Cooper MD, Wedgwood RJ. The primary immunodeficiencies. $N$ Engl J Med 1995; 17, 333: 431-40.

2. Buckley RH. Immunodeficiency diseases. JAMA 1992; 25, 268: 2797-806.

3. Aghamohammadi A, Moein M, Farhoudi A, et al. Primary immunodeficiency in Iran: first report of the National Registry of PID in Children and Adults. J Clin Immunol 2002; 22: 375-80.

4. Sweinberg SK, Wodell RA, Grodofsky MP, Greene JM, Conley ME. Retrospective analysis of the incidence of pulmonary disease in hypogammaglobulinemia. J Allergy Clin Immunol 1991; 88: 96-104.

5. Grenier P, Lenoir S, Brauner M. Computed tomographic assessment of bronchiectasis. Semin Ultrasound CT MR 1990; 11: 430-41.

6. Kornreich L, Horev G, Ziv N, Grunebaum M. Bronchiectasis in children: assessment by CT. Pediatr Radiol 1993; 23: 120-3.

7. McGuinness G, Naidich DP, Leitman BS, McCauley DI. Bronchiectasis: CT evaluation. Am J Roentgenol 1993; 160: 253-9.

8. Nicotra MB. Bronchiectasis. Semin Respir Infect 1994; 9: 31-40.

9. Young K, Aspestrand F, Kolbenstvedt A. High resolution CT and bronchography in the assessment of bronchiectasis. Acta Radiol 1991; 32: 439-41.

10. Herman M, Michalkova K, Kopriva F. High-resolution $\mathrm{CT}$ in the assessment of bronchiectasis in children. $P e$ diatr Radiol 1993; 23: 376-9. 
11. Bhalla M, Turcios N, Aponte V, et al. Cystic fibrosis: scoring system with thin-section CT. Radiology 1991; 179: 783-8.

12. Obregon RG, Lynch DA, Kaske T, Newell JD Jr, Kirkpatrick $\mathrm{CH}$. Radiologic findings of adult primary immunodeficiency disorders. Contribution of CT. Chest 1994; 106: 490-5.

13. Feydy A, Sibilia J, De Kerviler E, et al. Chest high resolution CT in adults with primary humoral immunodeficiency. Br J Radiol 1996; 69: 1108-16.
14. Curtin JJ, Webster AD, Farrant J, Katz D. Bronchiectasis in hypogammaglobulinaemia - a computed tomography assessment. Clin Radiol 1991; 44: 82-4.

15. Kainulainen L, Varpula M, Liippo K, Svedstrom E, Nikoskelainen J, Ruuskanen O. Pulmonary abnormalities in patients with primary hypogammaglobulinemia. J Allergy Clin Immunol 1999; 104: 1031-6.

16. Breatnach ES, Nath PH, McElvein RB. Preoperative evaluation of bronchiectasis by computed tomography. J Comput Assist Tomogr 1985; 9: 949-50.

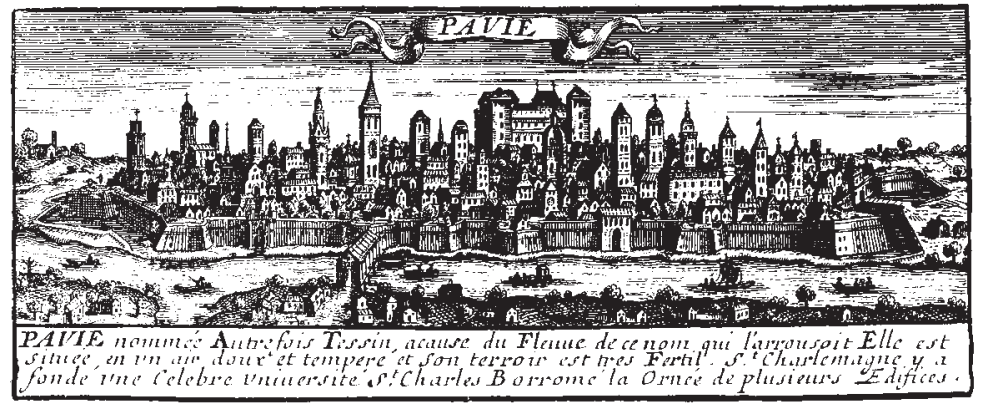

